\title{
Editorial
}

\section{Atmospheric Aerosols and Climate}

\section{Harry D. Kambezidis, ${ }^{1}$ Victoria E. Cachorro, ${ }^{2}$ Stefan Kinne, ${ }^{3}$ Krishnaswamy Krishnamoorthy, ${ }^{4}$ Gerrit de Leeuw, ${ }^{5,6}$ and Vito Vitale ${ }^{7}$}

\author{
${ }^{1}$ Atmospheric Research Team, National Observatory of Athens, 11810 Athens, Greece \\ ${ }^{2}$ Group of Atmospheric Optics, University of Valladolid, 47011 Valladolid, Spain \\ ${ }^{3}$ Max Planck Institute for Meteorology, 20146 Hamburg, Germany \\ ${ }^{4}$ Space Physics Laboratory, Vikram Sarabhai Space Centre, Trivandrum 695022, India \\ ${ }^{5}$ Climate Change Unit, Finnish Meteorological Institute, FI-00101 Helsinki, Finland \\ ${ }^{6}$ Department of Physics, University of Helsinki, FI-00014 Helsinki, Finland \\ ${ }^{7}$ Institute of Atmospheric Sciences and Climate, CNR, 40129 Bologna, Italy \\ Correspondence should be addressed to Harry D. Kambezidis, harry@noa.gr
}

Received 31 December 2010; Accepted 31 December 2010

Copyright (c) 2010 Harry D. Kambezidis et al. This is an open access article distributed under the Creative Commons Attribution License, which permits unrestricted use, distribution, and reproduction in any medium, provided the original work is properly cited.

Atmospheric aerosols affect the Earth's radiation budget directly by scattering and absorbing the solar and terrestrial radiation and indirectly by modifying the physical and radiative properties of clouds. Through their combined direct and indirect effects, anthropogenic aerosols have the potential to largely modify the albedo of the EarthAtmosphere system. Globally, the aerosol radiative forcing (ARF) is believed to be comparable in magnitude, but opposite in sign, to that caused by anthropogenic emissions of greenhouse gases; regionally, however, the magnitude and sign of ARF is highly variable, with large uncertainties, especially due to inadequate representation of the physical and radiative properties of aerosols in models.

Aerosols in areas influenced by anthropogenic activities are physically and chemically different from those in remote regions. These differences influence the aerosol optical properties. Knowledge of the aerosol properties is important for modelling the aerosol radiative effects on climate and retrieving the aerosol optical properties using remote-sensing techniques. Besides, changes in the vertical structure of the atmosphere lead to formation of distinct layers of aerosols above the planetary boundary layer; under favourable conditions, these aerosols are transported over long distances. The radiative implications of such elevated aerosols have immense impact on regional weather and climate.
The aim of this special issue is to provide the scientific community with a compendium of recent advances in the understanding of atmospheric aerosols and their impacts on climate. The seven accepted papers cover a wide range of the above issues. More specifically, they refer to the following topics:

(i) "Diagnosis of the relationship between dust storms over the Sahara desert and dust deposit or coloured rain in the South Balkans,"

(ii) "An assessment of the efficiency of dust regional modelling to predict Saharan dust transport episodes,"

(iii) "Identification of the aerosol types over Athens, Greece: the influence of air-mass transport,"

(iv) "Aerosol monitoring over Athens using satellite and ground-based measurements,"

(v) "Assessment of aerosol radiative impact over oceanic regions adjacent to Indian Subcontinent using multisatellite analysis,"

(vi) "Vertical and horizontal gradients in aerosol black carbon and its mass fraction to composite aerosols over the east coast of Peninsular India from aircraft measurements," 
(vii) "Urban surface temperature reduction via the urban aerosol direct effect-a remote sensing and WRF model sensitivity study."

\author{
Harry D. Kambezidis \\ Victoria E. Cachorro \\ Stefan Kinne \\ Krishnaswamy Krishnamoorthy \\ Gerrit de Leeuw \\ Vito Vitale
}



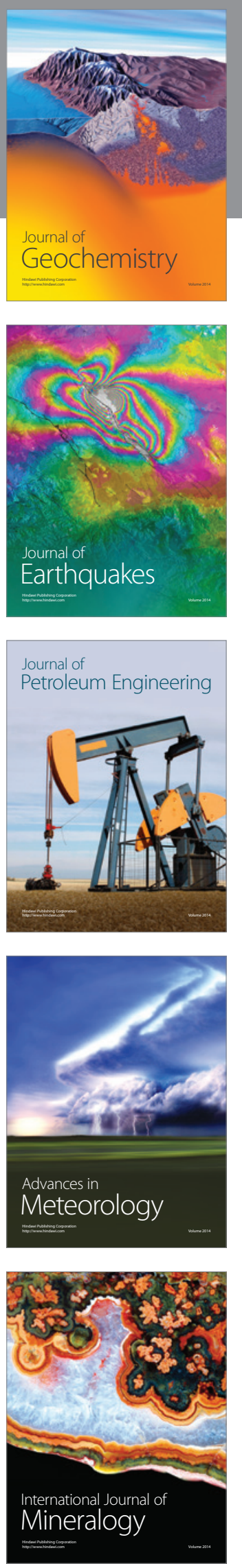
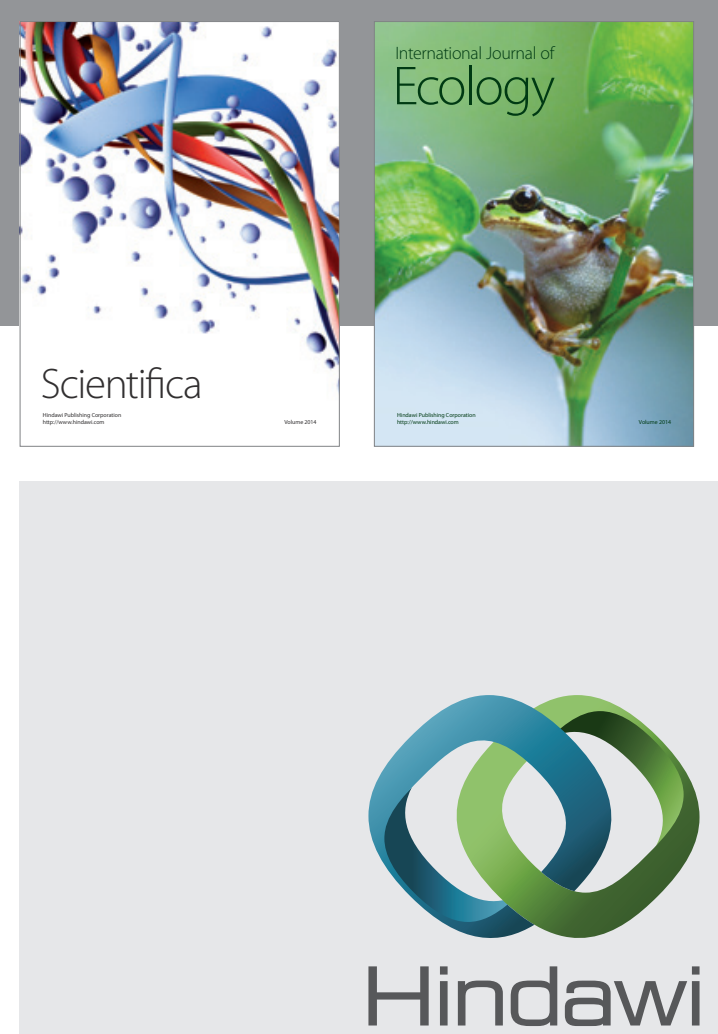

Submit your manuscripts at http://www.hindawi.com
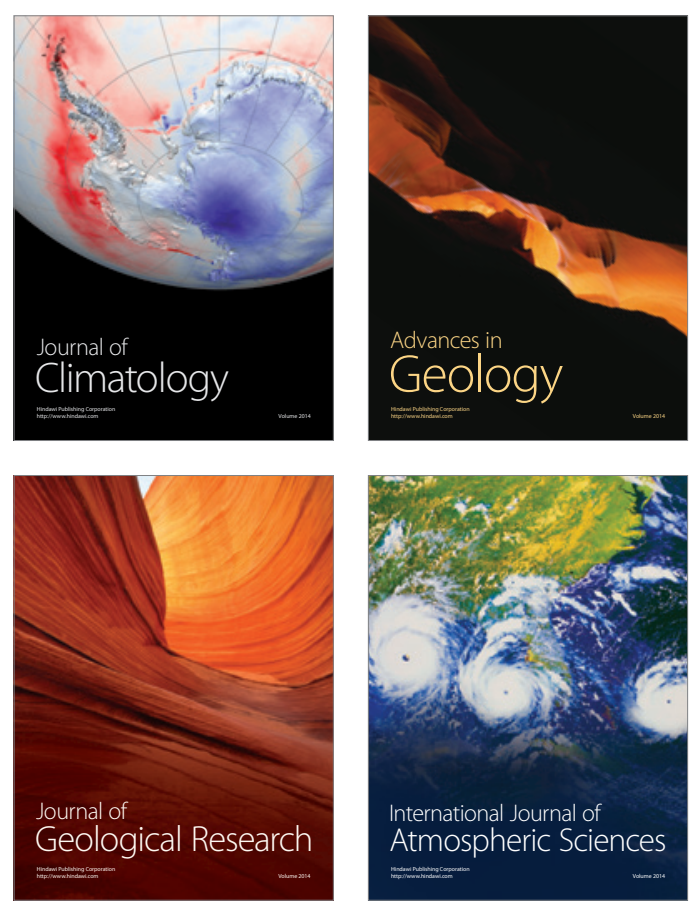
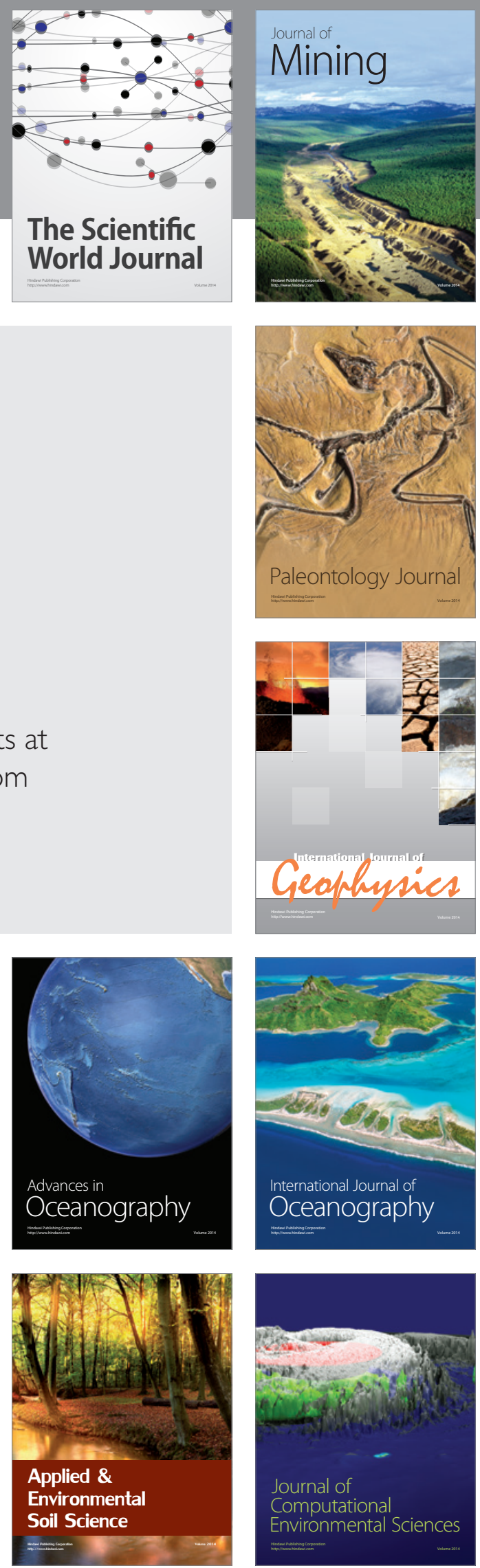